NASA/TM-2000-209802

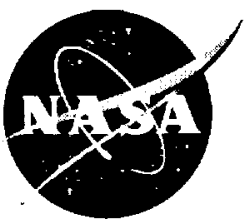

\title{
Parametric Study of Reactive Melt Infiltration
}

Emily S. Nelson

Glenn Research Center, Cleveland, Ohio

Phillip Colella

Lawrence Berkeley National Laboratory, Berkeley, California 
Since its founding, NASA has been dedicated to the advancement of aeronautics and space science. The NASA Scientific and Technical Information (STI) Program Office plays a key part in helping NASA maintain this important role.

The NASA STI Program Office is operated by Langley Research Center, the Lead Center for NASA's scientific and technical information. The NASA STI Program Office provides access to the NASA STI Database, the largest collection of aeronautical and space science STI in the world. The Program Office is also NASA's institutional mechanism for disseminating the results of its research and development activities. These results are published by NASA in the NASA STI Report Series, which includes the following report types:

- TECHNICAL PUBLICATION. Reports of completed research or a major significant phase of research that present the results of NASA programs and include extensive data or theoretical analysis. Includes compilations of significant scientific and technical data and information deemed to be of continuing reference value. NASA's counterpart of peerreviewed formal professional papers but has less stringent limitations on manuscript length and extent of graphic presentations.

- TECHNICAL MEMORANDUM. Scientific and technical findings that are preliminary or of specialized interest, e.g., quick release reports, working papers, and bibliographies that contain minimal annotation. Does not contain extensive analysis.

- CONTRACTOR REPORT. Scientific and technical findings by NASA-sponsored contractors and grantees.
- CONFERENCE PUBLICATION. Collected papers from scientific and technical conferences, symposia, seminars, or other meetings sponsored or cosponsored by NASA.

- SPECIAL PUBLICATION. Scientific, technical, or historical information from NASA programs, projects, and missions, often concerned with subjects having substantial public interest.

- TECHNICAL TRANSLATION. Englishlanguage translations of foreign scientific and technical material pertinent to NASA's mission.

Specialized services that complement the STI Program Office's diverse offerings include creating custom thesauri, building customized data bases, organizing and publishing research results ... even providing videos.

For more information about the NASA STI Program Office, see the following:

- Access the NASA STI Program Home Page at http://www.sti.nasa.gov

- E-mail your question via the Internet to help@sti.nasa.gov

- Fax your question to the NASA Access Help Desk at (301) 621-0134

- Telephone the NASA Access Help Desk at (301) 621-0390

- Write to: NASA Access Help Desk NASA Center for AeroSpace Information 7121 Standard Drive Hanover, MD 21076 
NASA/TM-2000-209802

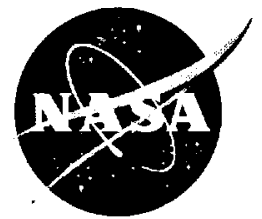

\title{
Parametric Study of Reactive Melt Infiltration
}

\author{
Emily S. Nelson
}

Glenn Research Center, Cleveland, Ohio

Phillip Colella

Lawrence Berkeley National Laboratory, Berkeley, California

Prepared for the

1999 International Mechanical Engineering Congress and Exposition

sponsored by the American Society of Mechanical Engineers

Nashville, Tennessee, November 14-19, 1999

National Aeronautics and

Space Administration

Glenn Research Center 


\section{Acknowledgments}

The authors would like to acknowledge NASA Glenn Research Center and the Department of Energy for their sponsorship of this work. The authors would also like to thank Jay Singh and Arnon Chait for their insightful review of this paper.

Available from

NASA Center for Aerospace Information 7121 Standard Drive

Hanover, MD 21076

Price Code: A03
National Technical Information Service 5285 Port Royal Road Springfield, VA 22100 Price Code: A03 


\title{
PARAMETRIC STUDY OF REACTIVE MELT INFILTRATION
}

\author{
Emily S. Nelson \\ National Aeronautics and Space Administration \\ Glenn Research Center \\ Cleveland, Ohio 44135 \\ Phillip Colella
Lawrence Berkeley National Laboratory \\ Berkeley, California 94720
}

\begin{abstract}
Reactive melt infiltration is viewed as a promising means of achieving near-net shape manufacturing with quick processing time and at low cost. Since the reactants and products are, in general, of varying density, overall conservation of mass dictates that there is a force related to chemical conversion which can directly influence infiltration behavior. In effect, the driving pressure forces may compete with the forces from chemical conversion, affecting the advancement of the front. We have developed a twodimensional numerical code to examine these effects, using reaction-formed silicon carbide as a model system for this process. We have examined a range of initial porosities, pore radii, and reaction rates in order to investigate their effects on infiltration dynamics.
\end{abstract}

\section{NOMENCLATURE}

\section{Roman letters}

$k_{r} \quad$ reaction rate constant

$M W_{t} \quad$ species molecular weight

$p \quad$ pressure

$r \quad$ pore radius

$R_{f} \quad$ rate of production/consumption of species $\ell$

$t_{e, i} \quad$ time at which infiltration is complete

$t_{e, r} \quad$ time at which chemical conversion is complete

$t_{3}$ time at which infiltration enters third, post-reaction-

dominated regime

$\tilde{u}_{D} \quad$ macroscopic Darcy (front) velocity

$\bar{v}_{C} \quad$ species molar specific volume

$v \quad$ volume

$y_{f} \quad$ location of the infiltration front

\section{Greek letters}

$\xi \quad$ intrinsic infiltration rate

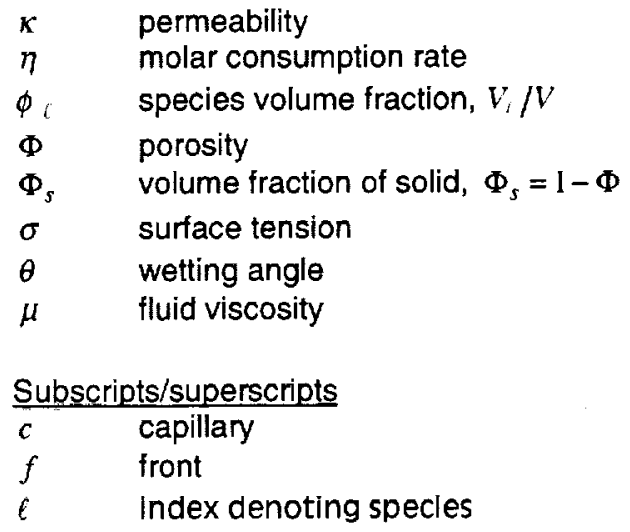

\section{BACKGROUND}

In reactive melt infiltration (RMI), a porous medium, or "preform", is first created, which is easy to form into a desired shape. A liquid infiltrant is introduced into the preform through a pressure gradient caused by capillary action or by applied pressure (see, e.g., Kochendoerfer, 1991; Hillig, 1994a, b; Haggerty and Chiang, 1990). The chemical conversion between the infiltrant and the preform results in a final product, which may be fully dense and is of the same dimensions as the original preform (Singh and Behrendt, 1992).

In comparison to other methods of composite manufacture, RMI is quick and efficient. Chemical vapor infiltration requires days or weeks to complete the chemical conversion process, but RMI needs only minutes or hours. Post-process machining is limited, making this process attractive for the manufacture of brittle and expensive ceramics.

Reaction-formed silicon carbide is chosen as a model system for this study. The production of monolithic silicon carbide system is appealing because the chemistry and 
preform geometry are reasonably well characterized. We will focus on infiltration that is driven solely by capillary pressure. The relevant thermophysical properties of the chemical constituents are given in Table 1.

Table 1. Thermophysical properties of silicon, carbon, and silicon carbide.

\begin{tabular}{|l|c|c|c|}
\hline \multicolumn{1}{|c|}{ Property } & Si & C & SiC \\
\hline$\rho\left(\mathrm{kg} / \mathrm{m}^{3}\right)$ & 2400 & 1500 & 3120 \\
\hline$\mu(\mathrm{kg} / \mathrm{m} \cdot \mathrm{s})$ & $5 \times 10^{-4}$ & & \\
\hline$M W(\mathrm{~kg} / \mathrm{kmol})$ & 28.1 & 12.0 & 40.1 \\
\hline$\overline{v_{1}}\left(\mathrm{~m}^{3} / \mathrm{kmol}\right)$ & 0.0117 & 0.008 & 0.0128 \\
\hline
\end{tabular}

Although the absolute viscosity of liquid silicon, $\mu$, is a weak function of temperature (Turovskii and Ivanova, 1974), we will neglect any temperature dependence. Note that the specific molar volume, $\bar{v}_{1}$, varies substantially among the species. In fact, the volume occupied by a mole of SiC is approximately $35 \%$ smaller than that of a mole each of Si and C. Based on overall mass conversion, Singh and Behrendt computed that the critical porosity, $\Phi_{c}$, for this process is 0.358 . For initial porosities below $\Phi_{c}$, the flow will choke prematurely because there simply is not enough volume available to complete the conversion. If $\Phi_{0}>\Phi_{c}$ and all of the carbon is converted in a fixed preform volume, the resulting ceramic will be comprised of SiC and Si. In this study, we will investigate $\Phi_{0}$ in the range of $0.40-0.60$, well above the critical porosity.

In order to model the preform, we have drawn on the extensive work of Behrendt and Singh on the melt infiltration of silicon and silicon alloys into microporous carbon (see Behrendt, 1986; Behrendt and Singh, 1993, 1994; Singh and Behrendt, 1992, 1994a, b, 1995). Their work was also the basis for other experimental and analytical studies (Sangsuwan et al., 1998; Datta et al., 1996; Messner and Chiang, 1990). The amorphous, glassy carbon preforms were uniform and isotropic with good connectivity (Singh and Behrendt, 1992, 1994b; Sangsuwan et al., 1998). Moreover, they could be consistently reproduced by Behrendt and Singh's process with pore diameters ranging from 0.1-3.0 $\mu \mathrm{m}$ and initial porosities from $0.33-0.64$. We will examine pore radii ranging from $0.10-0.20 \mu \mathrm{m}$ and initial porosities from 0.40-0.60.

Infiltration takes place in an evacuated furnace. Without the application of external pressure, the infiltration process is driven by capillary action. Consequently, the infiltration rate is dependent upon the wetting characteristics of the infiltrant upon the preform surface, which is in turn sensitive to local temperature and surface and melt impurities. At $1703 \mathrm{~K}$, the contact angle, $\theta$, of liquid silicon on carbon is reported to be $38^{\circ}$ by $\mathrm{LI}$ and Hausner (1991). (See also Whalen and Anderson, 1974; Turovskil and Ivanova, 1974.) We will use a value of $0.725 \mathrm{~N} / \mathrm{m}$ for the surface tension, $\sigma$ (Brandes, 1983), although other values have been reported (Minnear, 1982).
We will assume that the chemistry is reaction-controlled rather than diffusion-dominated, based on the work of Messner and Chiang (1990) and Fitzer and Gadow (1984) so that the pore radii close by:

$$
r(t)=r_{0}-k_{r} t_{r}
$$

where $r_{0}$ is the initial pore radius, $k_{r}$ is the reaction rate, and $i_{r}$. is the local reaction time, i.e., the amount of time that has elapsed since the reaction began in this region. Since the temperature variation within the preform for this set of parameters is on the order of $100^{\circ} \mathrm{C}$ (Nelson, 1998; Einset, 1993), we will use a constant value for $k_{r}$. Messner and Chiang estimated the reaction rate to be $4 \times 10^{-8} \mathrm{~m} / \mathrm{s}$, but bounded the estimate from $10^{-8}$ to $10^{-7} \mathrm{~m} / \mathrm{s}$. Alloyed melts may decrease reaction rates as well as eliminate the residual silicon phase (Singh and Behrendt, 1992, 1994a,b, 1995). Accordingly, we will investigate reaction rates in the range of $10^{-9}$ to $10^{-7} \mathrm{~m} / \mathrm{s}$. In reality, the reaction rate is not a tunable parameter, and the effect on infiltration dynamics will vary if the chemistry is modified.

\section{GOVERNING EQUATIONS}

A schematic of the two-dimensional numerical model of reactive melt infiltration is sketched below in Fig. 1. Liquid $S i$ is introduced at the bottom of the preform and wicks up into the preform due to capillary action.

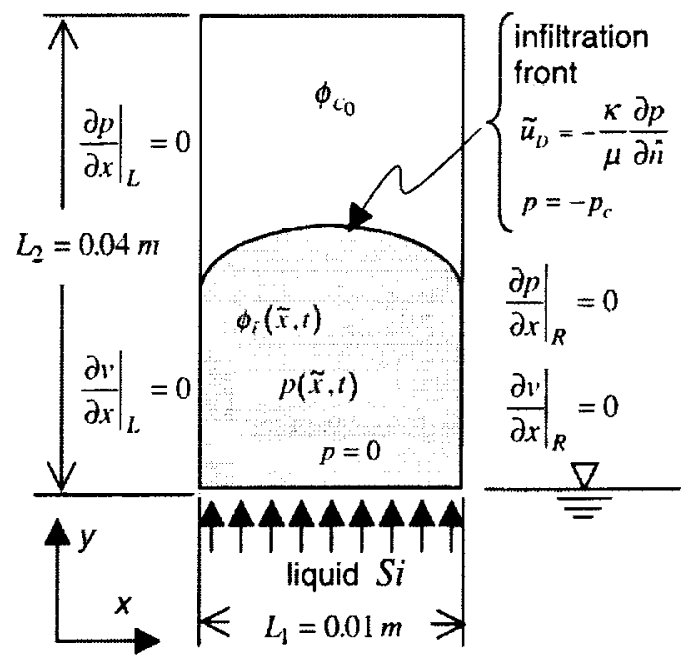

Figure 1. Schematic of reactive melt infiltration.

The general form for the conservation of mass is given for each of the species by:

$$
\frac{\partial}{\partial t}\left(\rho_{i} \phi_{\ell}\right)+\nabla \cdot\left(\rho_{i} \phi_{i} \tilde{u}_{i}\right)=R_{l} \quad \ell=S i, C, S i C
$$


where $R_{\ell}$ is the rate of production/destruction of species $\ell$, and $\phi_{l}$ is the species volume fraction, i.e., the fraction of the volume occupied by species $\ell$. The species volume fraction must obey the constraints $0 \leq \phi_{t} \leq 1$ and $\sum_{i} \phi_{i} \leq 1$. In any region that is completely filled, $\sum_{l} \phi_{!}=1$. Since overall mass must be conserved, the conservation equation for the total mass in the system is subject to the constraint $\sum R_{l}=0$. The liquid phase, comprised of a single component, i.e., $S i$, is the only phase with a nonzero velocity.

We will model this process as a zeroth-order chemical reaction. For stoichiometric conversion, this exothermic reaction is given by $\mathrm{Si}+\mathrm{C} \rightarrow \mathrm{SiC}$, so that the local production of species can be expressed as:

$$
R_{i}=\beta \eta M W_{l}
$$

where $\beta=+1$ for the product and -1 for the reactants, $\eta$ is the number of moles consumed per unit time, and $M W_{1}$ is the species molecular weight. We note that none of the species can be updated to a negative value. Since we are provided with an abundant source of $S i$, the amount of $C$ available locally will limit the chemical conversion. Therefore, when all of the $C$ has been consumed locally, the chemical reaction comes to a halt in that region.

We will make the critical assumption that the overall volume of the preform remains constant (Singh and Behrendt, 1992). Using the above assumptions, the overall conservation of mass can be written as:

$$
\nabla \cdot\left(\phi_{S i} \tilde{u}_{S i}\right)=\eta\left(\bar{v}_{S i C}-\bar{v}_{S i}-\bar{v}_{C}\right)
$$

where $\bar{r}_{i}=M W_{1} / \rho_{i}$ is the specific molar volume.

The expression for $\eta$ is found by relating the geometric description of the pore closure to that obtained from the conservation of mass. The volume fraction of the solid phase is $\Phi_{s}=\phi_{C}+\phi_{S i C}$. From mass conservation, the change in solid volume fraction with respect to time is:

$$
\begin{aligned}
\frac{\partial \Phi_{s}}{\partial t} & =\frac{\partial \phi_{C}}{\partial t}+\frac{\partial \phi_{S i C}}{\partial t} \\
& =\eta\left(\bar{v}_{S i C}-\bar{v}_{C}\right)
\end{aligned}
$$

If we envision the preform porosity to be comprised of a bundle of parallel capillary tubes, then the permeability for this model is found by:

$$
\kappa=\frac{\Phi r^{2}}{8}
$$

where $r$ is the pore radius and $\Phi$ is the porosity $\left(\Phi_{s}=1-\Phi\right)$. Experimental data (Datta et al., 1996) indicates that this is an adequate model for this preform. Comparing the crosssectional area of pore space initially and at time $n$, we find that:

$$
\frac{\partial \Phi_{s}}{\partial t}=\frac{\partial}{\partial t}\left(\frac{\Phi_{0}}{r_{0}^{2}}\left(r_{0}^{2}-r\left(t_{r}\right)^{2}\right)\right)
$$

For details, see Nelson, 1998; Nelson and Colella, 1999a,b. Recall that $r(t)=n_{0}-k_{r} t_{r}$, where $r_{0}$ is the initial pore radius and $t_{r}$ is the relevant reaction time. Combining Eqs. (5) and (7) gives the molar consumption rate as:

$$
\eta=\frac{2}{\bar{v}_{s i C}-\bar{v}_{C}} \frac{k_{r}}{r_{0}} \Phi_{0}\left(1-\frac{k_{r}}{r_{0}} t\right)
$$

At the pore level, the convective time scale is much longer than the diffusive time scale. Therefore, we can use d'Arcy's law to describe the motion of the front:

$$
\tilde{u}_{D}=-\frac{\widetilde{\kappa}}{\mu} \nabla p
$$

where $\tilde{u}_{D}$ is the front velocity, $\kappa$ is the permeability of the porous medium, $\mu$ is the absolute viscosity of the fluid, and $p$ is the pressure. For this system, $\kappa$ is a function of space and time. Furthermore, any body force term is negligible in comparison to the pressure force provided by capillary action.

We can relate the fluid velocity, $\tilde{u}_{S i}$, to the front velocity, $\tilde{u}_{D}$, by the Dupuit-Forcheimer relation, i.e., $\tilde{u}_{D}=\phi_{S i} \tilde{u}_{S i}$. We do not explicitly know $\tilde{u}_{D}$ or the pressure field; however, our analysis of continuity provided a relationship for the divergence of velocity in Eq. (4). Combining the divergence of d'Arcy's law, Eq. (9), with Eq. (4), we arrive at a steady Poisson problem for pressure that stems from the conservation of momentum and of mass:

$$
\nabla\left(-\frac{\kappa}{\mu} \nabla p\right)=\eta\left(\bar{v}_{S i C}-\bar{v}_{S i}-\bar{v}_{C}\right)
$$

Equation (10) identifies the mechanism by which capillary forces and chemical conversion can enter into competition in the infiltration process. For this system, the right-hand side of Eq. (10) is at minimum zero. When it is nonzero, the pressure profiles within the preform exhibit some curvature, resulting in a nonuniform velocity field.

For this system, the ambient pressure is negligible. We apply a homogeneous Dirichlet boundary condition at the lower boundary; at the infiltration front, the pressure is equal to the negative of the capillary pressure, $-p_{c}$. Using the YoungLaplace equation, we can estimate $p_{c}$ at the front as a function of surface tension, $\sigma$, pore radius, $r$, and the contact angle, $\theta$ :

$$
p_{c}=\frac{2 \sigma \cos \theta}{r}
$$

Depending on the initial pore radius, $p_{c}$ varied from about $5.94 \times 10^{6}$ to $1.88 \times 10^{7} \mathrm{~Pa}$. As in the experimental selup of Sangsuwan et al. (1998), we will assume that the preform is 
coated with, e.g., boron nitride, to inhibit mass transport across the sidewalls. This ensures that the liquid silicon from the bath will not wick up the sidewalls, and that no fluid will escape from the system through the sidewalls. Therefore, homogeneous Neumann boundary conditions are applied to the pressure at the side boundaries.

After the pressure solve, we can directly calculate the velocity from the pressure field by using d'Arcy's law, Eq. (9). The normal component of velocity at the sidewalls is zero, due to the homogenous Neumann boundary condition used on the pressure field. Although we would expect some tangential velocity slip in the immediate vicinity of the sidewalls, these effects are confined to distances on the order of a pore diameter (Kaviany, 1991). Therefore, we will assume that, at the left and right boundaries, $\partial y / \partial x=0$. In this set of numerical simulations, the infiltration process is essentially one-dimensional, as in experimental work of a similar process (Einset, 1993). This can be expected due to uniform initial porosity and pore size, the choice of boundary conditions on pressure and velocity, and the simplicity of the chemistry and permeability models.

The derivation of the energy equation, as well as the full details of the above derivations, can be found in Nelson (1998) or Nelson and Colella (2000b).

\section{NUMERICAL PROCEDURE}

The equations derived above are used to develop a finitevolume algorithm for reactive melt infiltration. The discrete formulation in two dimensions is discussed in Nelson (1998) and Nelson and Colella (2000a). Briefly, the macroscople velocity is used to advance the front on a fixed mesh using a front-tracking technique developed by Chern and Colella (1988), coupled with a volume-of-fluid method and front reconstruction. Chemical reaction is allowed to occur based on the local species volume fractions and local reaction time. The updated species volume fractions are used to form a new permeability field. Next, a Poisson problem is solved on the infiltrated region only to find the new pressure field, using the technique of Johansen and Colella (1998). Finally, d'Arcy's law is used to find the new velocity field. The process is repeated until all of the $C$ in the preform is consumed or the final simulation time is reached.

The mesh size was $32 \times 128$ on a $0.01 \times 0.04 \mathrm{~m}$ domain so that the mesh spacing $\Delta x=\Delta y=0.0003125 \mathrm{~m}$. A description of the discrete equations, as well as the effects of grid resolution and other sources of numerical error are discussed in Neison and Colella (2000a) and Nelson (1998).

\section{RESULTS}

In this section, we will explore the effects of varying reaction rate, initial porosity and initial pore radius.

\section{Effect of reaction rate}

With the initial porosity fixed at 0.50 and the initial pore radius at $0.17 \mu \mathrm{m}$, the infiltration curves for reaction rates of 0 , $10^{-9}, 10^{-8}$, and $10^{-7} \mathrm{~m} / \mathrm{s}$ are shown below in Fig. 2. The capillary pressure corresponding to this case is $6.99 \times 10^{6} \mathrm{~Pa}$. Fig. 2(a) presents the location of the front at the centerline, $y_{f}(t)$, while Fig. 2(b) shows $y_{f}^{2}(t)$.

In the absence of chemical reaction, $y_{f}(t)$ exhibits a square-root dependence, and the slope of $y_{f}^{2}(t)$, called the intrinsic infiltration rate (Hillig, 1994b) and denoted as $\xi$, is constant. The front reaches the upper boundary of the preform, located at $0.04 \mathrm{~m}$, at $t_{i}=15.51 \mathrm{~s}$. (a)

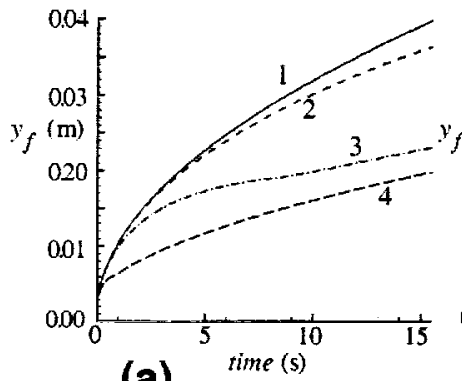

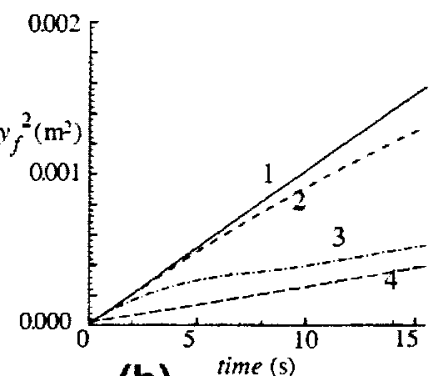

(b)
Figure 2. Centerline infiltration profiles for $\Phi_{0}=0.50$; $r_{0}=0.17 \mu \mathrm{m} ; k_{r}=0(1), 10^{-9}(2), 10^{-8}(3)$, and $10^{-7}$ (4) $\mathrm{m} / \mathrm{s}$. (a) $y_{f}(t)$; (b) $y_{f}{ }^{2}(t)$

For the chemical system of Si/C/SiC, the infiltration process is retarded by the chemical reaction. For the low reaction rate, $k_{r}=10^{-9} \mathrm{~m} / \mathrm{s}$, the infiltration curves closely match the nonreacting case for the first couple of seconds. After that point, the front begins to lag behind the nonreacting case. Fig. 2(b) shows that that $\xi$ is not constant over this time interval. In contrast, $y_{f}^{2}$ for $k_{r}=10^{-7} \mathrm{~m} / \mathrm{s}$ appears quite linear after half a second. For $k_{r}=10^{-8} \mathrm{~m} / \mathrm{s}$, there is a short period of under one second during which the curves closely follow the nonreacting profiles. Up to about 8 seconds, the slope of $y_{f}^{2}$ is continuously changing. After that time, $\xi$ appears constant, nearly matching that of $k_{r}=10^{-7} \mathrm{~m} / \mathrm{s}$.

What explains this behavior? The infiltration moves through a sequence of flow regimes in which the forces induced by capillary action and by chemical reaction are in competition (Nelson, 1998; Nelson and Colella, 2000a, b). Initially, the pressure forces dominate as the infiltrant impulsively moves into the preform, indicated through the close correspondence of $y_{f}$ with the nonreacting case. This can be seen in approximately the first two seconds of $k_{r}=10^{-9}$ $\mathrm{m} / \mathrm{s}$ and the first second of $k_{r}=10^{-8} \mathrm{~m} / \mathrm{s}$.

In the second regime, the forcing term provided by the chemical reaction flares up and wanes. Within the preform, 


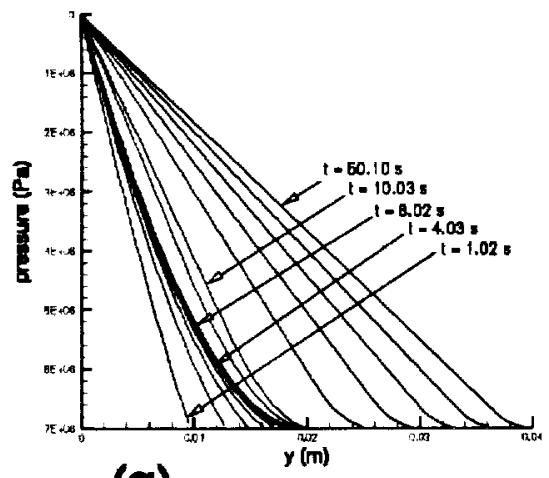

(a)

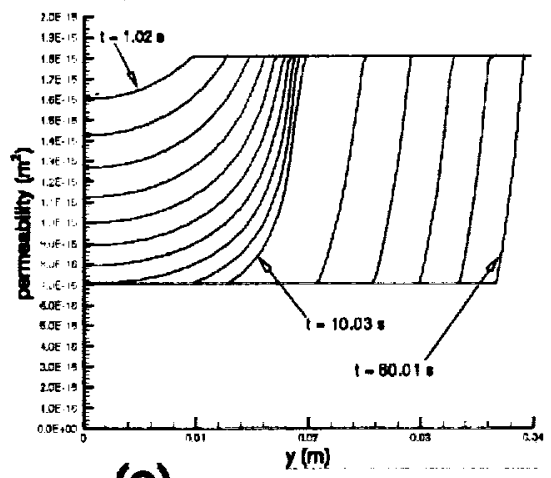

(c)

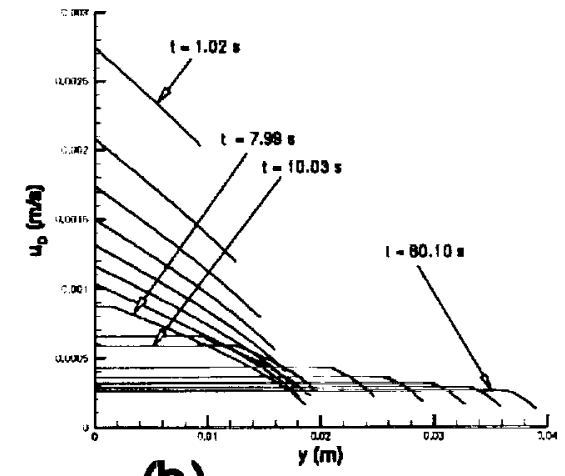

(b)

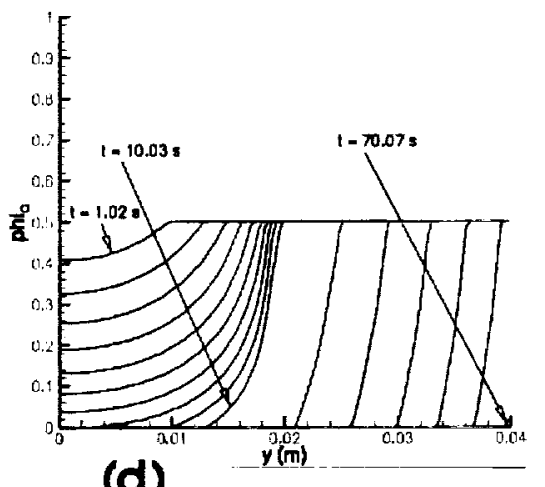

(d)

Figure 3. Centerline profiles of (a) pressure; (b) velocity; (c) permeability; and (d) $\phi_{c}$ for $\Phi_{0}=0.50, r_{0}=0.17 \mu \mathrm{m}$, and $k_{r}=10^{-8} \mathrm{~m} / \mathrm{s}$. Profiles are presented in approximately one-second increments for $t=1-5$ seconds, and in ten-second increments thereafter.

the centerline pressure profiles become progressively more curved (see Eq. (13)), leading to decreased flow velocities (see Eq. (9)), as shown in Figs. 3(a) and (b) for $k_{r}=10^{-8} \mathrm{~m} / \mathrm{s}$. Behind the front, the permeability, $\kappa$, Fig. $3(\mathrm{c})$, and $\phi_{c}$, Fig. 3(d), steadily decrease. Previous work (Nelson, 1998, Nelson and Colella, 2000a, b) indicates that the centerline thermal maximum lags well behind the infiltration front in this regime. Furthermore, the maximum operating temperatures were observed in this regime, particularly with insulated boundaries nearby.

When all of the available $C$ has been consumed near the entry to the preform. Fig. 3 (d) at $t=7.99 \mathrm{~s}$, the pressure relaxes to a more linear profile except in the immediate vicinity of the front, Fig. 3(a). Correspondingly, the velocity profile becomes constant over part of the infiltrated region, Fig. 3(b). Consequently, $y_{f}(t)$ exhibits the characteristic bump in the infiltration profiles of Fig. 2, e.g., in $k_{r}=10^{-8} \mathrm{~m} / \mathrm{s}$ between 4 and 8 seconds. This behavior can be observed in experimental work by Einset (1996).

For $k_{r}=10^{-9} \mathrm{~m} / \mathrm{s}$, the infiltration is still early in the reaction-dominated regime at 15 seconds, while for $k_{r}=10^{-7}$ $\mathrm{m} / \mathrm{s}$, the infiltration has passed through the reaction-dominated regime by about one-half second. As will be seen throughout this work, the temporal and physical extent of the reactiondominated regime decreases with increasing reaction rate.

After 10 seconds, the infiltration process for $k_{r}=10^{-8} \mathrm{~m} / \mathrm{s}$ enters a third regime, in which the reaction-generated forces are confined to a small region behind the front and the infiltration dynamics are largely set by the permeability in the fully reacted zone and the capillary pressure. From 10 seconds to complete infiltration at 63 seconds, $y_{f}(t)$ resembles a square-root profile, and $\xi$ can be approximated by a constant. The reaction zone becomes progressively more localized to the vicinity of the front. For example, the reacting zone at 63 seconds is about $0.00296 \mathrm{~m}$, appearing over eight computational cells. As a result, the thermal maximum is very close to the infiltration front (Nelson, 1998).

Although the curve for the highest reaction rate in Fig. 2(b) appears linear after one second, notice that, unlike the nonreacting case, the curve does not intersect the origin. Examination of the initial time interval more closely indicates that the infiltration simply proceeds through the reactiondominated regime more rapidly than the other cases, resulting in the offset. If we were to extend the temporal window for 


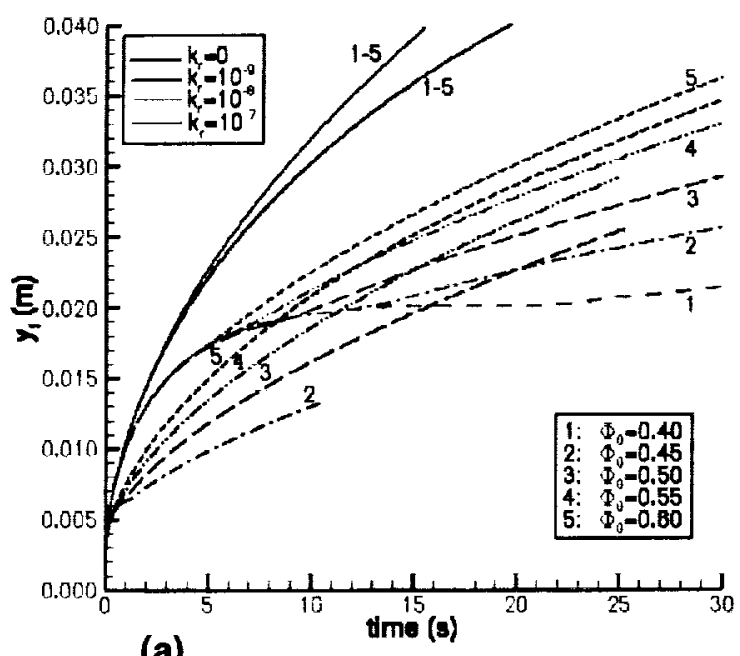

(a)

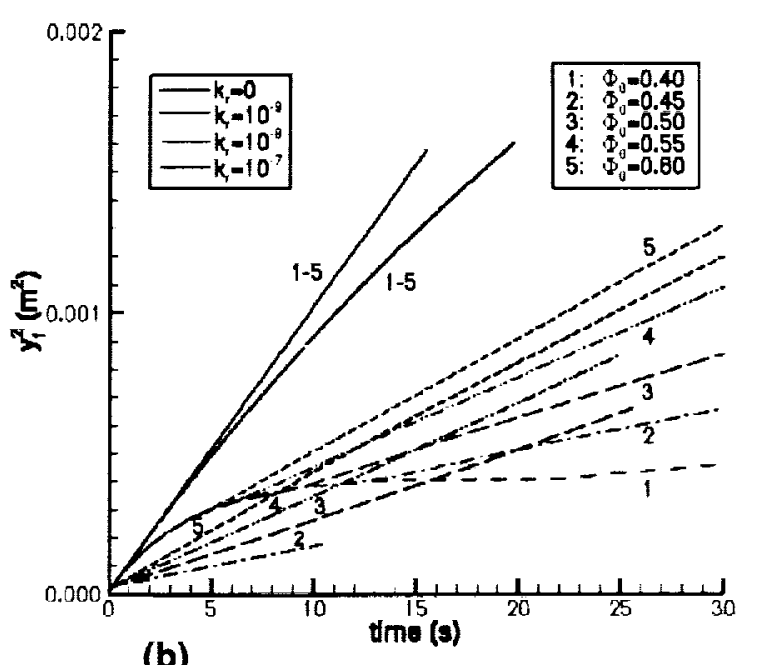

(b)

Figure 4. Effect of $\Phi_{0}$ on infiltration profiles for $r_{0}=0.17 \mu \mathrm{m}$ and $\Phi_{0}=0.40(1), 0.45(2), 0.50(3), 0.55$ (4) and 0.60 (5): $k_{r}=0$ (black), $10^{-9}$ (blue), $10^{-8}$ (green), and $10^{-7} \mathrm{~m} / \mathrm{s}$ (red): (a) $y_{f}$ vs. $t$; (b) $y_{f}{ }^{2}(t)$ vs. $t$.

$k_{r}=10^{-9} \mathrm{~m} / \mathrm{s}$ to later times (and with a longer preform length, in most cases), we would also see the characteristic bump signaling the ascendance and conclusion of the reactiondominated regime, but occurring at a retarded pace.

When fully reacted, the final value for $\phi_{S i}$ is 0.197 and for $\phi_{S i C}$, it is 0.803 .

\section{Effect of initial porosity}

To examine the effect of varying porosity, infiltration profiles are shown in Fig. 4 for $k_{r}=0,10^{-9}, 10^{-8}$, and $10^{-7} \mathrm{~m} / \mathrm{s}$ with $\Phi_{0}=0.40,0.45,0.50,0.55$ and 0.60 , holding $r_{0}$ fixed at $0.17 \mu \mathrm{m}$. The capillary pressure corresponding to this $r_{0}$ is $6.99 \times 10^{6} \mathrm{~Pa}$. In this time interval, the infiltration profiles for $k_{r}=0$ and $10^{-9} \mathrm{~m} / \mathrm{s}$ collapse into two curves. The increased permeability caused by increasing the porosity by $50 \%$ does not significantly impact the infiltration in the pressuredominated regime and the early stages of the reactiondominated regime.

At increased reaction rate, we can still see an early period during which the curves for the varying porosity are indistinguishable. However, in the subsequent reactiondominated regime, Fig. 4 indicates that the reaction-generated forces can greatly slow down the infiltration, as seen most dramatically for $k_{r}=10^{-8} \mathrm{~m} / \mathrm{s}$ at the lowest porosities. In fact, the reaction-generated forces can theoretically stop the flow for a time. The fanning effect seen for $k_{r}=10^{-8}$ and $10^{-7} \mathrm{~m} / \mathrm{s}$ can be explained as follows: Since carbon is the only species present in the preform initially, $\Phi_{0}$ is related to the amount of $C$ present, i.e., $\phi C_{o}=1-\Phi_{0}$. This in effect places an upper bound on the amount of chemical conversion that is possible over a given volume. Once the carbon in the initial reactiondominated region is consumed, the dynamics of the infiltration proceed at a different pace. At constant $k_{r}$, examination of the centerline profiles reveal that the fanning occurs soon after the pressure profile relaxes back from its most distorted shape. These trends indicate that the reaction-dominated regime becomes larger in spatial and temporal extent with decreasing porosity and reaction rate. For the fully reacted zone, the final $\phi_{S i C}$ was $0.96,0.88,0.80,0.72$, and 0.64 for $\Phi_{0}=0.40,0.45,0.50,0.55$ and 0.60 , respectively.

The times required for complete infiltration and complete conversion, $t_{e, i}$ and $t_{e, r}$, are presented in Fig. 5. We did not carry out the infiltration process to complete conversion for $k_{r}=10^{-7} \mathrm{~m} / \mathrm{s}$ due to numerical instability; this is being

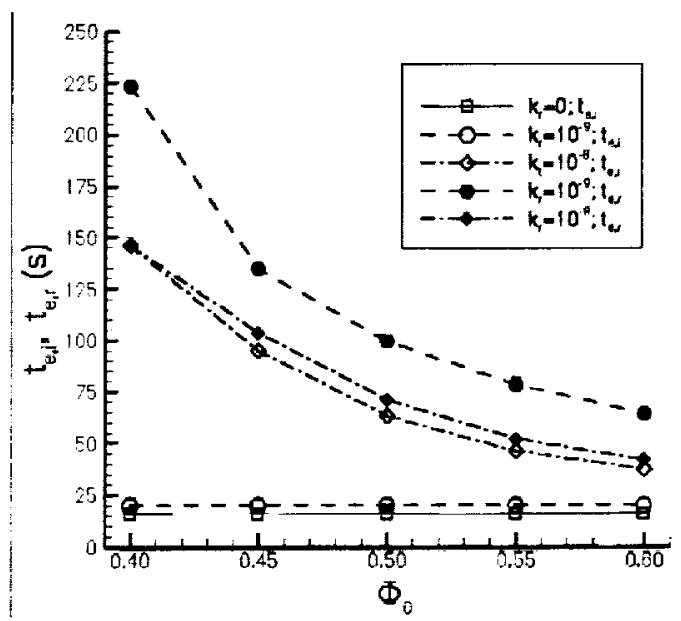

Figure 5. Influence of $\Phi_{0}$ on required time for complete infiltration (unfilled symbols) and conversion (filled symbols) for $r_{0}=0.17 \mu \mathrm{m}$ and $k_{r}=0, \square ; 10^{-9}$, ; and $10^{-8}$ $\mathrm{m} / \mathrm{s}, \bullet$ 
addressed in a modified algorithm (Nelson and Colella, 2000a).

Notice that the most efficient reaction rate for infiltrating the preform, i.e., the lowest $k_{r}$, does not imply the shortest conversion time, particularly at low initial porosities. Also note that, as the reaction rate is increased at fixed porosity, the difference between $t_{e, c}$ and $t_{e, i}$ decreases. It is zero for $\Phi_{0}=0.40, k_{r}=10^{-8} \mathrm{~m} / \mathrm{s}$, indicating that the carbon behind the front is essentially consumed as fast as the front can move.
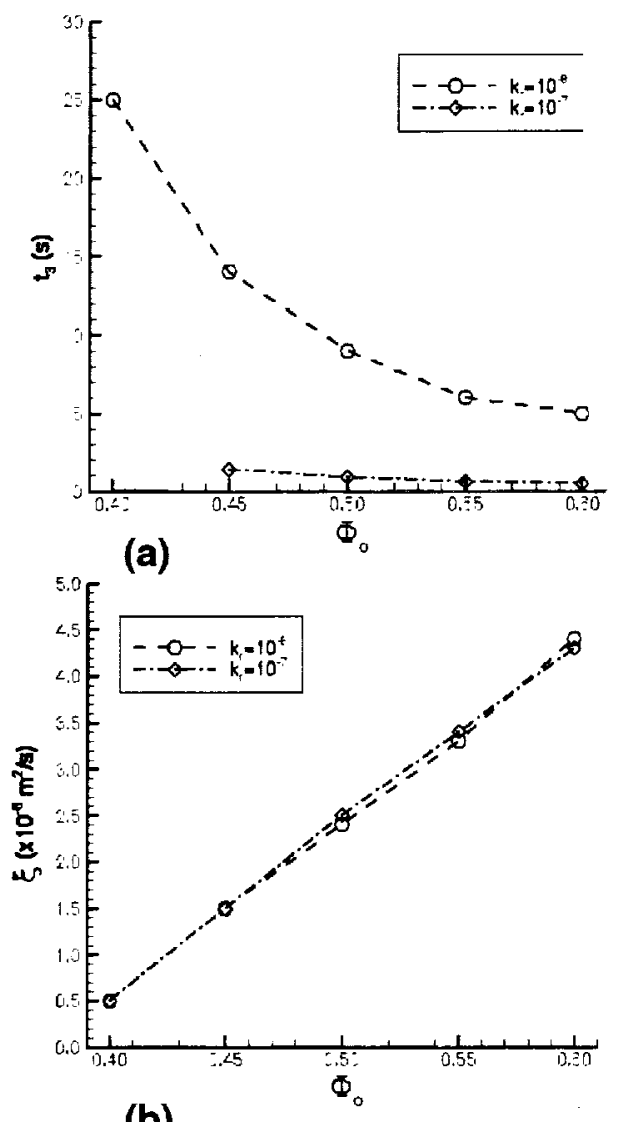

(b)

Figure 6. Influence of $\Phi_{0}$ in the post-reaction-dominated regime: (a) time of entry into this regime; and (b) intrinsic infiltration rate.

The time at which the infiltration moved from the reactiondominated regime to the third post-reaction-dominated regime, $t_{3}$, shown in Fig. 6(a), was estimated from infiltration profiles. The intrinsic infiltration rate, $\xi$, in this regime is presented in Fig. 6(b).
For $k_{r}=0, \xi=1.0 \times 10^{-4} \mathrm{~m} / \mathrm{s}$ over the range of porosity. For $k_{r}=10^{-8} \mathrm{~m} / \mathrm{s}$ and $10^{-7} \mathrm{~m} / \mathrm{s}$, we can see that $\xi$ increases linearly with porosity. We might expect this, because the permeability is proportional to the porosity, while capillary pressure remains fixed. When chemical reaction occurs, the entry into the post-reaction-dominated regime is retarded as porosity decreases, reflecting the increased influence of the reaction-generated forces on the infiltration dynamics. However, once in the post-reaction-dominated regime, the permeability in the fully reacted zone behind the front is more influential on the infiltration dynamics than the reactiongenerated forces.

\section{Effect of initial pore radius}

Next, we will examine the influence of the initial pore radius on the infiltration process, holding the porosity fixed at $\Phi_{0}=0.50$ and varying the reaction rate, $k_{r}$, to $0,10^{-9}, 10^{-8}$, $10^{-7} \mathrm{~m} / \mathrm{s}$ and the pore radius to $0.10,0.14,0.17$ and $0.20 \mu \mathrm{m}$. The capillary pressure corresponding to these pore radii ranges from $5.94 \times 10^{6} \mathrm{~Pa}$ to $1.88 \times 10^{7} \mathrm{~Pa}$ (see Eq. (11)). For clarity, the infiltration curves are presented in sets by reaction rate in Fig. 7 for the first 30 seconds of the infiltration.

Decreasing pore radius retards the infiltration, as observed by Einset (1996) experimentally. Ignoring the chemical reaction for the moment, this would be expected since the capillary pressure is inversely proportional to $r_{0}$, while the permeability is proportional to $r_{0}^{2}$. Unlike the parameterization in porosity, the curves for $k_{r}=0$ and $10^{-9} \mathrm{~m} / \mathrm{s}$ do not collapse onto one another in Figs. 7(a) and (b). We also see the effects of chemistry in the curves for $k_{r}=10^{-8}$ and $10^{-7}$ $\mathrm{m} / \mathrm{s}$ in Figs. $7(\mathrm{c})$ and (d).

The curves for $k_{r}=10^{-9} \mathrm{~m} / \mathrm{s}$ (Fig. $7(\mathrm{~b})$ ) are nearly equivalent to the corresponding nonreacting case for the first second or two. All of the preforms at this reaction rate are fully saturated by 30 seconds except for $r_{0}=0.10 \mu \mathrm{m}$. The intrinsic infiltration rate, $\xi$, shown in Fig. $7(f)$ is not constant for any of the pore radii over this time interval.

The characteristic bump in the infiltration profile due to the presence of the reaction-dominated regime is seen most clearly in Fig. 7 (c) for $k_{r}=10^{-8} \mathrm{~m} / \mathrm{s}$ under 10 seconds. The corresponding slope of $y_{f}^{2}(t)$ in Fig. $7(g)$ is not linear during this time. The infiltration has moved beyond the reactiondominated regime by 10 seconds in Fig. 7(c). This occurs more quickly for the higher reaction rate in less than a second in Fig. $7(\mathrm{~d})$. From Figs. $7(\mathrm{~g})$ and $(\mathrm{h})$, we can see that $\xi$ appears constant once the infiltration process has left the reaction-dominated regime. 


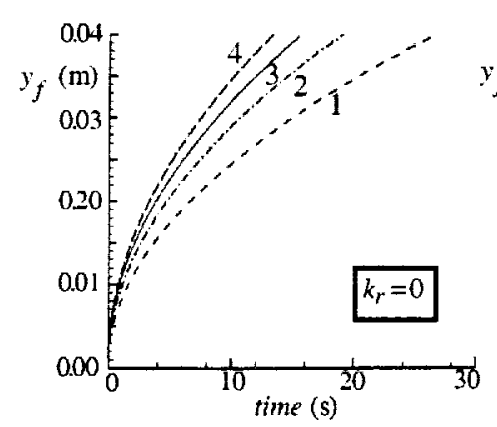

(a)

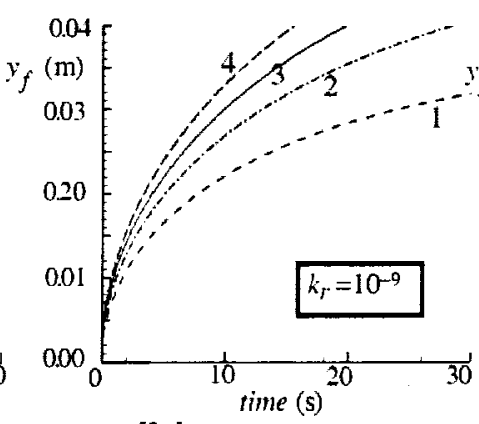

(b)

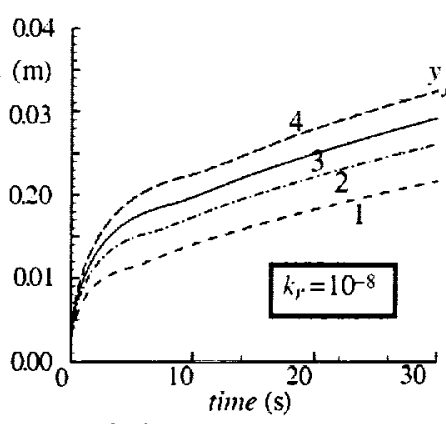

(c)

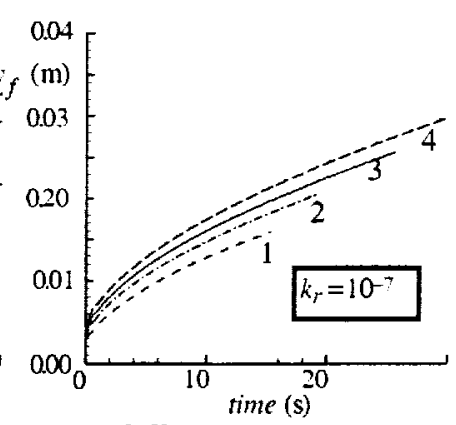

(d)

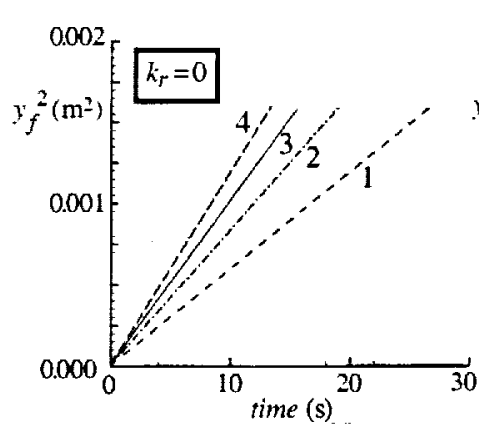

(e)

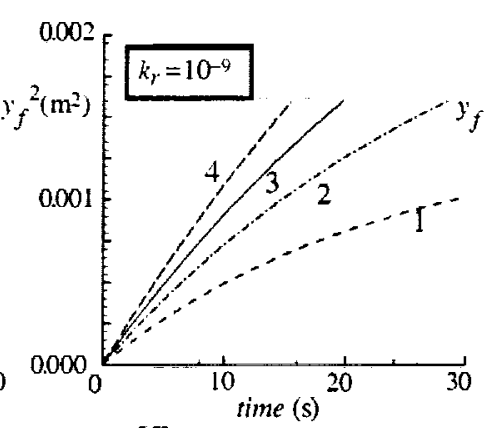

(f)

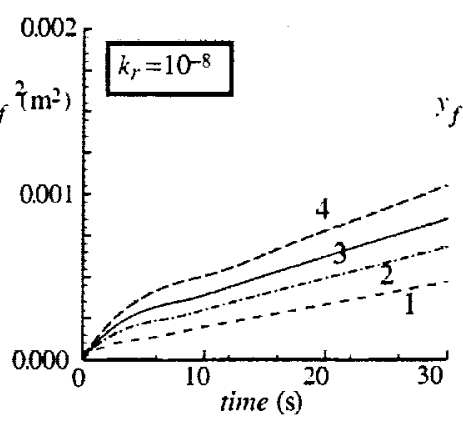

(g)

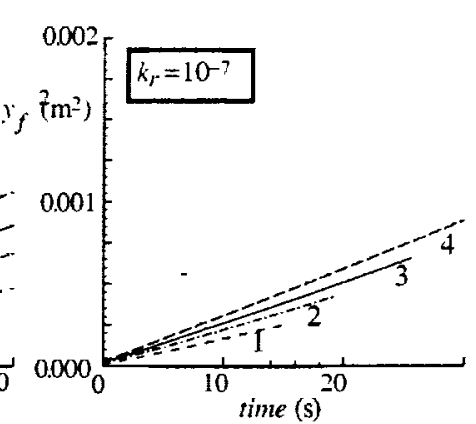

(h)

Figure 7. Effect of $r_{0}$ on infiltration profiles for $\Phi_{0}=0.50 ; r_{0}=0.10(1), 0.14(2), 0.17$ (3) and 0.20 (4) $\mu \mathrm{m}$ : (a) $y_{f}(r), k_{r}=0.0 ;(b)$ $y_{f}(t), \quad k_{r}=10^{-9} \mathrm{~m} / \mathrm{s} ;$ (c) $y_{f}(t), \quad k_{r}=10^{-8} \mathrm{~m} / \mathrm{s} ;$ and (d) $y_{f}(t), \quad k_{r}=10^{-7} \mathrm{~m} / \mathrm{s} ;$ (e) $y_{f}^{2}(t), \quad k_{r}=0.0 ;(f) y_{f}{ }^{2}(t), \quad k_{r}=10^{-9} \mathrm{~m} / \mathbf{s} ;(\mathrm{g})$ $y_{f}^{2}(t), \quad k_{r}=10^{-8} \mathrm{~m} / \mathrm{s}$; and $(\mathrm{h}) y_{f}^{2}(t), k_{r}=10^{-7} \mathrm{~m} / \mathrm{s}$.

The dependence of the total infiltration and conversion times on pore radius is shown in Fig. 8. A wide gap is once again apparent between $t_{e, i}$ and $t_{e, r}$ for $k_{r}=10^{-9} \mathrm{~m} / \mathrm{s}$ (unfilled and filled circles). For the lowest pore radius and reaction rate (filled circle, left of arrow), the infiltration process had moved well beyond the reaction-dominated regime when the upper boundary was encountered. On the other hand, much of the conversion took place in a fully saturated preform for the larger pore radii (filled circles, right of arrow). Recall that, for a fully saturated preform, the pore radius decreases linearly with time, Eq. (1), to complete conversion. The trend of increasing $t_{e, r}$ with increasing radius at high pore radii therefore indicates that, under these conditions, the absence of the front reduces the effectiveness of the conversion.

Figure 9 shows the influence of pore radius on the start of the post-reaction-dominated regime and on the intrinsic infiltration rate. Fig. 9(a) indicates that decreasing pore radius reduces the temporal extent of the reaction-dominated regime, an effect which is most pronounced at the lower reaction rate. Unlike the porosity-dependent parameterization, $\xi$ is not constant for $k_{l}=0$ (squares), but rather increases with increasing pore radius, due to increasing permeability. As before, we should expect this because the capillary pressure is inversely proportional to $r_{0}$, while the permeability is proportional to $r_{0}^{2}$. Fig. $9(b)$ indicates that $\xi$ is linearly proportional to $r_{0}$ and is not affected greatly by the reaction rate. These results imply that the infiltration in the postreaction-dominated regime is governed primarily by the permeability of the preform in the reacted zone behind the front and by the capillary pressure.

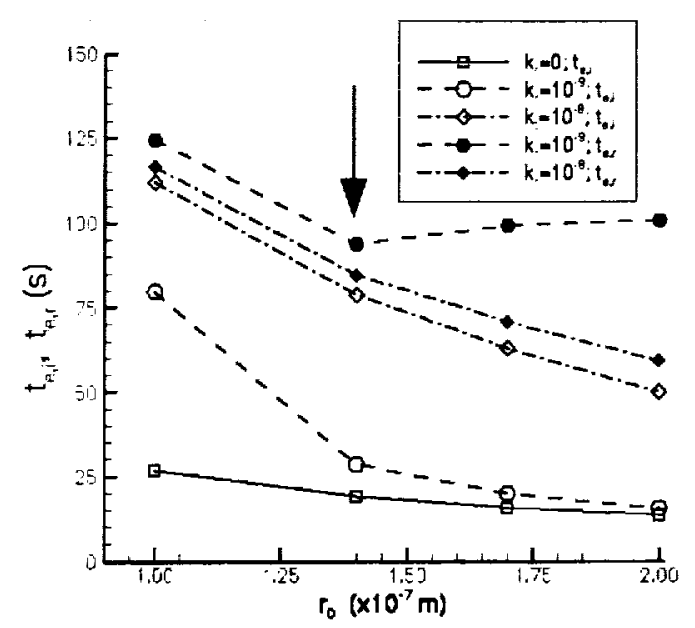

Figure 8. Influence of $r_{0}$ on required time for complete infiltration (unfilled symbols) and complete conversion (filled symbols) for $k_{r}=0, \square ; 10^{-9}, \bullet$; and $10^{-8} \mathrm{~m} / \mathrm{s}$, 

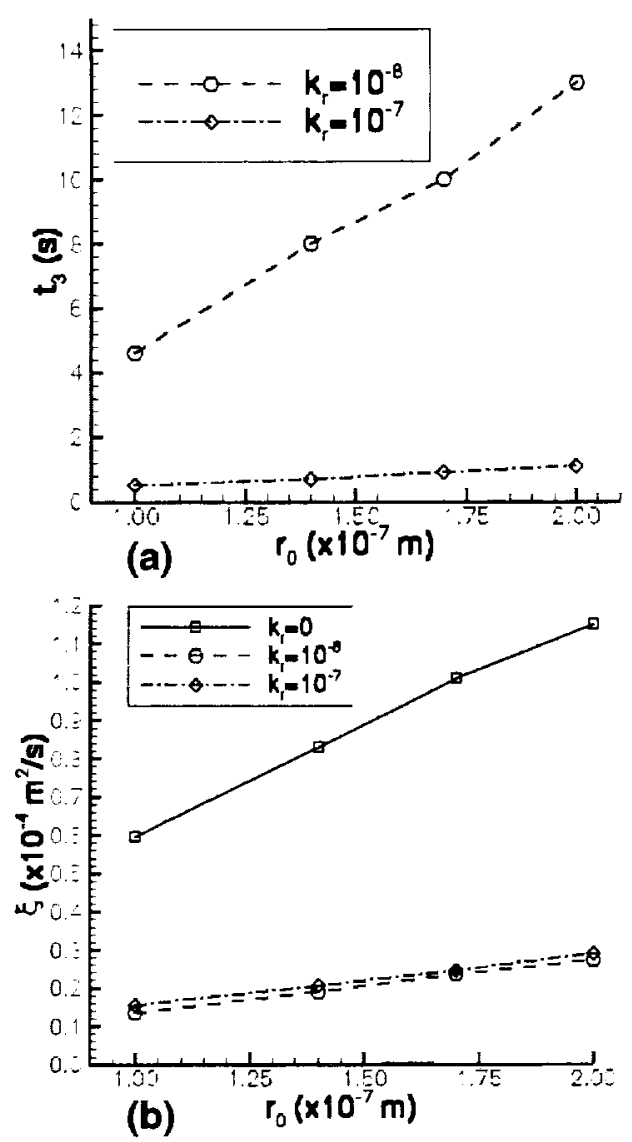

Figure 9. Influence of $r_{0}$ in the post-reaction-dominated regime: (a) time of entry into this regime; and (b) intrinsic infiltration rate.

\section{CONCLUSIONS}

We have examined the infiltration of liquid $S i$ into a constant-volume microporous $C$ preform to form a monolithic SiC ceramic composite for the range of $\Phi_{0}=0.40-0.60$, $r_{0}=0.10-0.20 \mu \mathrm{m}$, and $k_{r}=0,10^{-9}, 10^{-8}, 10^{-7} \mathrm{~m} / \mathrm{s}$. The initial pore radius and porosity were uniform over the entire preform.

We have seen that the infiltration dynamics are dependent on reaction rate, initial porosity and initial pore radius. Significantly, it is also a function of the flow regime arising from the competition between pressure and reaction forces. We did not find a simple correlation for the time and distance associated with the reaction-dominated regime. However, numerical simulation can be used to predict these details.

Initially, the pressure forces dominated as the infiltrant - impulsively entered the preform. Later, the presence of the chemical reaction retarded the infiltration due to a competition between the pressure forces and the volumetric forces due to the chemical conversion. When the reactants in the entry to the preform were consumed, the reaction zone was confined to a small region behind the front. Furthermore, the infiltration rate increased, although it was significantly smaller than that of the corresponding nonreacting case.

In the first pressure-dominated regime and the early stages of the second reaction-dominated regime, a porosity increase of $50 \%$ had a negligible effect on the infiltration profiles, as seen in the data for $k_{\text {. }}=0$ and $10^{-9} \mathrm{~m} / \mathrm{s}$.

The reaction-generated forces may impede or enhance the flow, depending on the density variation among the products and reactants. For the Si/C/SiC system with a dense product, the conversion was shown to retard the flow. The temporal and physical extent of the reaction-dominated regime decreased with increasing reaction rate, decreasing pore radius and increasing porosity. In this regime, the velocity within the preform was retarded significantly due to the curvature of the pressure profiles, causing a characteristic bump in the infiltration profiles. Theoretically, the flow can become stationary at the front; this is to be distinguished from choking in that this is a temporary phenomenon. For $k_{r}=10^{-8}$ $\mathrm{m} / \mathrm{s}$, the reaction-dominated regime was in evidence from about 2 to 10 seconds, while it was completed by one second for $k_{r}=10^{-7} \mathrm{~m} / \mathrm{s}$. The intrinsic infiltration rate was not constant in this regime, indicating that the location of the front did not have a square-root dependence on time. Aside from the implications on infiltration dynamics, the maximum process temperature was found, in previous work, to occur in this regime. The reaction-dominated regime ended soon after the carbon in the initial entry zone was completely consumed.

Beyond the reaction-dominated regime, the infiltration settled into a simpler pattern. The reaction zone was localized to an area just behind the front. The intrinsic infiltration rate was constant and proportional to the initial porosity and to the initial pore radius. Although the permeability is proportional to the square of the pore radius, the capillary pressure is inversely proportional to the pore radius, accounting for this behavior. The intrinsic infiltration rate was not greatly influenced by the magnitude of the reaction rate in this regime. We therefore deduce that the infiltration was primarliy affected by the capillary pressure at the front and the permeability in the fully reacted zone behind the front. Consequently, the intrinsic infiltration rate can be characterized by a constant beyond the reaction-dominated regime, although the line representing $\xi t$ must be offset from the origin to coincide with the data.

For this system, numerical simulation of the parameter space provides the best prediction of optimal parameters for minimum conversion time. For an actual process, we should also include preform length as a parameter, as that will affect whether or not the process leaves the reaction-dominated regime. For $k_{r}=10^{-9} \mathrm{~m} / \mathrm{s}$, the infiltration was completed during the early stages of the reaction-dominated regime, except at the smallest pore radii. If the entire preform reached saluration during this time, the overall conversion time was seen to increase with increasing pore radius, since the evolving pore radius decreased strictly linearly with time, as set by the chemistry of the system. In contrast, if the infiltration moved into the post-reaction-dominated regime, as seen at lower pore 
radius, the conversion time decreased with increasing pore radius. The presence of the advancing front, with its accompanying complex infiltration dynamics, can either improve or reduce the efficiency of the conversion process, depending on the initial parameters. If the infiltration was allowed to proceed through the sequence of infiltration regimes, the overall conversion time decreased with increasing porosity, pore radius and reaction rate.

This sort of analysis could provide insight into the design of functionally graded materials. For example, local modification of the pore radius or porosity in the post-reactiondominated regime could be used to speed up the infiltration rate. Such a modification in the reaction-dominated regime could have major implications on the efficiency of the process. The advantage of a numerical simulation is that it could range over the desired parameter space with minimal effort, allowing for more precise optimization.

\section{References}

Behrendt, D.R. "Porous silicon carbide as a matrix for ceramic composites." NASA TM 88837 (1986).

Behrendt, D.R. and M. Singh. "Effect of carbon preform pore volume and infiltrants on the composition of reactionformed silicon carbide materials." $J$ Mat Synthesis and Processing 2:117-123 (1994).

Behrendt, D.R. and M. Singh. "Theoretical considerations for reaction-formed silicon carbide." NASA TM 106414 (1993).

Brandes, E.A., ed. Smithells Metals Reference Book, $6^{\text {th }}$ ed. Butterworths (1983).

Chern, $I-L$ and $P$. Colella. "A conservative front tracking method for hyperbolic conservation laws". Unpublished paper (1988).

Datta, S.K., N. Simhai, S.N. Tewari, J.E. Gatica, and M. Singh. "Permeability of microporous carbon preforms." Met Trans A 27A:3669-74 (1996).

Einset, E. O. Private communication (1993).

Einset, E. O. "Capillary infiltration rates into porous media with applications to Silcomp processing." J Am Ceram SoC 79.333-338 (1996).

Fitzer, E. and R. Gadow. "Investigations of the reactivity of different carbons with liquid silicon." In Proceedings of International symposium on ceramic components for engines. Japan, 1983. KTK Scientific Publishers, Tokyo, Japan (1984).

Haggerty, J.S. and Y.M. Chiang. "Reaction-based processing methods for ceramics and composites." Ceram Eng and Sci Proc 11:757-781 (1990).

Hillig, W.B. "Making ceramic composites by melt infiltration." Am Ceram Soc Bull 73.56-62 (1994).

Hillig, W.B. "Melt infiltration approach to ceramic matrix composites." Am Ceram Soc, Comm 71:C-96 to C-99 (1994).

Hillig, W.B., R.L. Mehan, C.R. Morelock, V.J. DeCarlo and W. Laskow. "Silicon/silicon carbide composites." Amer Ceram Soc Bull 54:1054-56 (1975).
Johansen, $H$. and Colella, P. "A Cartesian grid embedded boundary method for Poisson's equation on irregular domains." J Comp Phys 147:60-85 (1998).

Kaviany, M. "Principles of heat transfer in porous media." Springer-Verlag (1991).

Kochendoerfer, R. "Liquid silicon infiltration: a fast and low-cost CMC manufacturing process." In Composites: Proceedings of the 8th International Conference on Composite Materials. Held in Honolulu, HI, July 15-19, 1991, pp. 23-F-1 to 23-F-9.3 (1991).

Li, J.G. and H. Hausner. "Wettability of silicon carbide by gold, germanium and silicon." J Mat Sci Ltrs 10:1275-76 (1991).

Messner, R. and Y.M. Chiang. "Liquid-phase reactionbonding of silicon carbide using alloyed Si-Mo melts." J Amer Ceram Soc 73:1193 (1990).

Minnear, W.P. "Interfacial energies in the Si/SiC system and the Si+C reaction." $J$ Amer Ceram Soc 65:C10-C11 (1982)

Nelson, E.S. "A numerical algorithm for the simulation of reactive melt infiltration." Ph.D. Thesis. University of California at Berkeley (1998).

Nelson, E.S. and P. Colella. "A numerical algorithm for reactive melt infiltration." To be submitted to $J$ Comp Phys (2000a).

Nelson, E.S. and P. Colella. "Infiltration dynamics in reactive melt infiltration." To be submitted to $J$ Amer Ceram $\operatorname{Soc}(2000 b)$.

Nelson, E.S. and P. Colella. Unpublished work (2000c).

Sangsuwan, P., S.N. Tewari, J.E. Gatica, M. Singh and R. Dickerson. "Reactive infiltration of silicon melt through microporous amorphous carbon preforms." Met Trans 308.933-944 (1998).

Singh, M. and D.R. Behrendt. "Reactive melt infiltration of silicon-molybdenum alloys into microporous carbon preforms." Mat Sci Eng A 194:193-200 (1995).

Singh. M. and D.R. Behrendt. "Microstructure and mechanical properties of reaction-formed silicon carbide (RSFC) ceramics." Mat Sci Eng A 187:183-187 (1994).

Singh, M. and D.R. Behrendt. "Reactive melt infiltration of silicon-niobium alloys in microporous carbons." $J$ Mat Res 7:1701-1708 (1994).

Singh. M. and D.R. Behrendt. "Studies on the reactive melt infiltration of silicon and silicon-molybdenum alloys in porous carbon." NASA TM 105860 (1992).

Turovskii, B.M. and I.I. Ivanova. "Temperature dependence of the viscosity of fused silicon." Inorganic Materials 10.2108-2111 (1974).

Whalen, T.J. and A.T. Anderson. "Wetting of $\mathrm{SiC}_{1} \mathrm{Si}_{3} \mathrm{~N}_{4}$, and carbon by Si and binary Si alloys." $J A m$ Ceram SoC 58:396-399 (1974). 


\section{$\checkmark$}

-

- 


\begin{tabular}{|c|c|c|c|c|}
\hline \multicolumn{3}{|c|}{ REPORT DOCUMENTATION PAGE } & \multicolumn{2}{|r|}{$\begin{array}{l}\text { Form Approved } \\
\text { OMB No. 0704-0188 }\end{array}$} \\
\hline \multicolumn{5}{|c|}{ 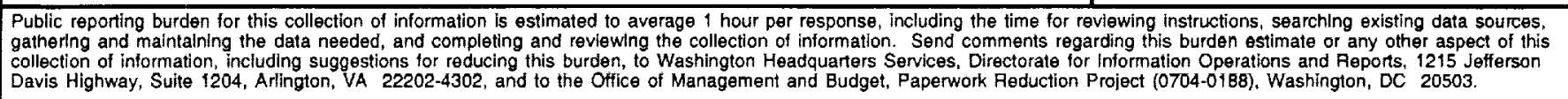 } \\
\hline 1. AGENCY USE ONLY (Leave blank) & \multicolumn{4}{|c|}{\begin{tabular}{|c|c|} 
2. REPORT DATE & 3. REPOAT TYPE AND DATES COVEAED \\
March 2000 & Technical Memorandum
\end{tabular}} \\
\hline \multicolumn{3}{|c|}{$\begin{array}{l}\text { 4. TITLE AND SUBTITLE } \\
\text { Parametric Study of Reactive Melt Infiltration }\end{array}$} & \multirow{2}{*}{\multicolumn{2}{|c|}{$\begin{array}{l}\text { 5. FUNDING NUMBERS } \\
\text { WU-101-43-0C-00 }\end{array}$}} \\
\hline \multicolumn{3}{|c|}{$\begin{array}{l}\text { 6. AUTHOR(S) } \\
\text { Emily S. Nelson and Phillip Colella }\end{array}$} & & \\
\hline \multicolumn{3}{|c|}{$\begin{array}{l}\text { 7. PERFORMING ORGANIZATION NAME(S) AND ADDRESS(ES) } \\
\text { National Aeronautics and Space Administration } \\
\text { John H. Glenn Research Center at Lewis Field } \\
\text { Cleveland, Ohio } 44135-3191\end{array}$} & \multicolumn{2}{|c|}{$\begin{array}{l}\text { 8. PERFORMING ORGANIZATION } \\
\text { REPORT NUMBER } \\
\text { E-12107 }\end{array}$} \\
\hline \multicolumn{3}{|c|}{$\begin{array}{l}\text { 9. SPONSORING/MONITORING AGENCY NAME(S) AND ADDRESS(ES) } \\
\text { National Aeronautics and Space Administration } \\
\text { Washington, DC 20546-0001 }\end{array}$} & \multicolumn{2}{|c|}{$\begin{array}{l}\text { 10. SPONSORING/MONITORING } \\
\text { AGENCY REPORT NUMBER } \\
\text { NASA TM-2000-209802 }\end{array}$} \\
\hline \multicolumn{5}{|c|}{$\begin{array}{l}\text { 11. SUPPLEMENTARY NOTES } \\
\text { Prepared for the } 1999 \text { International Mechanical Engineering Congress and Exposition sponsored by the American } \\
\text { Society of Mechanical Engineers, Nashville, Tennessee, November 14-19, 1999. Emily S. Nelson, NASA Glenn Re- } \\
\text { search Center, and Phillip Colella, Lawrence Berkeley National Laboratory, M-S 50D-133, Berkeley, California } 94720 \text {. } \\
\text { Responsible person, Emily S. Nelson, organization code } 6727,(216) 433-3268 \text {. }\end{array}$} \\
\hline \multicolumn{3}{|c|}{$\begin{array}{l}\text { 12a. DISTRIBUTION/AVAILABILITY STATEMENT } \\
\text { Unclassified - Unlimited } \\
\text { Subject Categories: } 24,27 \text { and } 34 \quad \text { Distribution: Nonstandard } \\
\text { This publication is available from the NASA Center for AeroSpace Information, (301) 621-0390. }\end{array}$} & \multicolumn{2}{|c|}{ 12b. DISTRIBUTION CODE } \\
\hline \multicolumn{5}{|c|}{$\begin{array}{l}\text { Reactive melt infiltration is viewed as a promising means of achieving near-net shape manufacturing with quick process- } \\
\text { ing time and at low cost. Since the reactants and products are, in general, of varying density, overall conservation of mass } \\
\text { dictates that there is a force related to chemical conversion which can directly influence infiltration behavior. In effect, the } \\
\text { driving pressure forces may compete with the forces from chemical conversion, affecting the advancement of the front. } \\
\text { We have developed a two-dimensional numerical code to examine these effects, using reaction-formed silicon carbide as a } \\
\text { model system for this process. We have examined a range of initial porosities, pore radii, and reaction rates in order to } \\
\text { investigate their effects on infiltration dynamics. }\end{array}$} \\
\hline \multirow{2}{*}{\multicolumn{4}{|c|}{$\begin{array}{l}\text { 14. SUBJECT TERMS } \\
\text { Infiltration; Porosity; Composite materials; Silicon carbides; Porous materials; Reacting } \\
\text { flow; Fluid dynamics; Manufacturing; Production engineering; Permeability }\end{array}$}} & 15. NUMBER OF PAGES \\
\hline & & & & $\begin{array}{c}16 \\
\text { 16. PRICE CODE } \\
\text { A03 }\end{array}$ \\
\hline $\begin{array}{l}\text { 17. SECURITY CLASSIFICATION } \\
\text { OF REPOAT } \\
\text { Unclassified }\end{array}$ & $\begin{array}{l}\text { 18. SECURITY CLASSIFICATION } \\
\text { OF THIS PAGE } \\
\text { Unclassified }\end{array}$ & $\begin{array}{l}\text { 19. SECURITY CLASSIFICA } \\
\text { OF ABSTRACT } \\
\text { Unclassified }\end{array}$ & TION & 20. LIMITATION OF ABSTRACT \\
\hline
\end{tabular}

